\title{
Caracterización de corredores gastronómicos como elementos turísticos potenciales en zonas rurales. Caso de estudio: la zona central de Manabí-Ecuador
}

\section{Characterization of food routes as potential tourist elements in rural areas. Case study: the central zone of Manabí-Ecuador}

\author{
Ángel Guillermo Félix Mendoza ${ }^{*}$. Diana Anjuly Vera Intriago ${ }^{2}$, \\ Josselyn Karolina Cevallos Cevallos ${ }^{3}$
}

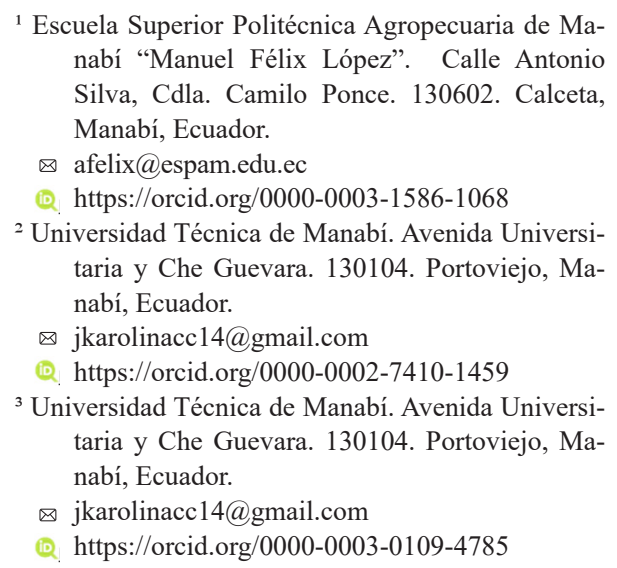

${ }^{1}$ Escuela Superior Politécnica Agropecuaria de Manabí "Manuel Félix López". Calle Antonio Silva, Cdla. Camilo Ponce. 130602. Calceta, Manabí, Ecuador.

$\bowtie$ afelix@espam.edu.ec

https://orcid.org/0000-0003-1586-1068

${ }^{2}$ Universidad Técnica de Manabí. Avenida Universitaria y Che Guevara. 130104. Portoviejo, Manabí, Ecuador.

凶jkarolinacc14@gmail.com

2. https://orcid.org/0000-0002-7410-1459

${ }^{3}$ Universidad Técnica de Manabí. Avenida Universitaria y Che Guevara. 130104. Portoviejo, Manabí, Ecuador.

$\otimes$ jkarolinacc14@gmail.com

Q. https://orcid.org/0000-0003-0109-4785

*Autor de correspondencia: afelix@espam.edu.ec

\section{SIEMBRA}

https://revistadigital.uce.edu.ec/index.php/SIEMBRA ISSN-e: 2477-8850

\section{ISSN: $1390-8928$}

Periodicidad: semestral

vol. 8, núm. 2, 2021

siembra.fag@uce.edu.ec

DOI: https://doi.org/10.29166/siembra.v8i2.2908

Esta obra está bajo una licencia internacional Creative Commons Atribución-NoComercial

\section{Resumen}

La gastronomía se ha convertido en uno de los productos emblemáticos del turismo tanto en el ámbito patrimonial de los territorios como en el contexto rural. El objetivo de la presente investigación es el de caracterizar varios corredores gastronómicos ubicados en la zona central interna de la provincia de Manabí-Ecuador. La investigación es exploratoria, con un enfoque cualitativo; para la caracterización de los corredores se establecieron ciertos criterios de selección tomados de entrevistas con autoridades locales y provinciales, también se utilizaron fichas de diagnóstico local y estudio de demanda en comunidades. Se realizó la georreferenciación satelital mediante la utilización de dispositivos GPS (Garmin Etrex 20x), estos datos fueron procesados a través de sistemas de información geográfica, específicamente los softwares SAS Planet para la descarga de imágenes satelitales y Arc Gis para los mapas. Se identificaron 5 corredores gastronómicos representativos en la zona central de la provincia de Manabí; los mismos poseen atractivos naturales como ríos, riveras de ríos y cascadas, además de una gran cantidad de negocios asociados al concepto de la gastronomía típica manabita de interior. Los corredores se encuentran ubicados en los cantones de Chone, Bolívar, Santa Ana, Rocafuerte y Tosagua; agrupan a 58 establecimientos gastronómicos, los mismos que atienden a miles de turistas durante los fines de semanas. Existe poca concentración de negocios de alojamiento, en comparación con los de alimentación, lo que nos indica claramente que son destinos para turismo de cercanía, los cuales poseen un gran potencial para ampliar sus servicios y la estancia de los visitantes.

Palabras clave: turismo rural, turismo gastronómico, productos turísticos, gastronomía, agroturismo.

\begin{abstract}
Gastronomy has become one of the emblematic products of tourism, both in the heritage area of the territories and in the rural context. The objective of this research is to characterize several food routes located in the central internal zone of the province of Manabí-Ecuador. The research is exploratory, with a qualitative approach; for the characterization of the routes, certain selection criteria were established, taken from interviews
\end{abstract}


with local and provincial authorities, local diagnosis sheets and a study of demand in communities were also used. Satellite georeferencing was carried out using GPS devices (Garmin Etrex 20x), these data were processed through Geographic Information Systems, specifically the Arc Gis and SAS Planet. Five representative food routes were identified in the central area of the Manabí province, they have natural attractions such as rivers, river banks and waterfalls, as well as a large number of businesses associated with the concept of typical Manabí gastronomy. The rputes are located in the cantons of Chone, Bolívar, Santa Ana, Rocafuerte and Tosagua, they group 58 gastronomic establishments, the same ones that serve thousands peoples during the weekends. There is little concentration of accommodation businesses, compared to food, which clearly indicates that they are suburban destinations, which have great potential to expand their services and the stay of visitors.

Keywords: rural tourism, gastronomic tourism, tourist products, gastronomy, agrotourism.

\section{Introducción}

Las llegadas de turistas internacionales en todo el mundo respecto al año 2019 crecieron un $4 \%$ hasta alcanzar los 1.500 millones. Fue otro año de fuerte crecimiento, aunque más lento en comparación con las tasas excepcionales de 2017 (+ 7 \%) y 2018 (+ $6 \%$ ). La demanda fue más lenta principalmente en las economías avanzadas y particularmente en Europa. Sobre la base de las tendencias actuales, las perspectivas económicas y el índice de confianza de la Organización Mundial del Turismo [OMT], se pronostica un crecimiento del $3 \%$ al $4 \%$ en las llegadas de turistas internacionales en todo el mundo en 2020 (OMT, 2020). Sin embargo, nada de esto sucederá, debido a la presencia de un nuevo y peligroso enemigo para la actividad turística mundial, la pandemia de corona virus 2019 (COVID-19) (Félix et al., 2020).

Es por ello que el propósito de la presente investigación es el de caracterizar varios corredores gastronómicos ubicados en la zona central interna de la provincia de Manabí- Ecuador, mediante la revisión bibliográfica y el levantamiento de información en el área de estudio, de manera que se permita mostrar la gran acogida que tiene este turismo gastronómico ante la situación actual del sector turístico. Aclarando esta circunstancia inicial, la experiencia previa nos permitió identificar la vertiginosidad con la que crecía el sector, la cual es poco comparable con algún sector de la economía tradicional. Por tal motivo se precisa un nivel de exigencia superlativo en el análisis, sistematización y planificación, para la prestación y el consumo de los servicios turísticos en el territorio (Boullón, 2006). La ausencia de la planificación ha provocado una serie de complicaciones, en muchos casos irreversibles para ciertos destinos con alta afluencia turística; uno de los problemas cuya solución se ha encarado tímidamente en América Latina es el del ordenamiento territorial del espacio en que se desenvuelven las actividades turísticas (Boullón, 2006).

Pese a las dificultades de planificación en los territorios, se debe reconocer el aporte del turismo a la revitalización económica local y nacional. La inyección del dinero generado por el gasto turístico a una economía local tiene tres tipos de impactos: directos, indirectos e inducidos (Brida et al., 2017). Todos estos tipos de impactos tienen una serie de ventajas en la balanza de pagos de una nación, por esta razón es importante identificar nuevas oportunidades para la atracción de nuevos visitantes. Según Aguirregoitia Martínez y Fernández-Poyatos (2017) la transformación que ha caracterizado al mercado turístico en las últimas décadas ha señalado la necesidad, por parte del mercado y de los viajeros, de categorizar las diferentes tipologías de turismo que el demandante puede encontrar en una localidad determinada; en este contexto, la gastronomía ha adquirido una gran importancia en los últimos años, convirtiéndose así en uno de los recursos turísticos más atractivos para promocionar.

Se debe tener en cuenta que la alimentación puede ser un elemento primario o secundario en un viaje, ya que hay turistas que "se alimentan", para ellos la alimentación es un elemento secundario en los viajes que realizan; y otros turistas que "viajan para comer". Los primeros, en su viaje solamente se alimentan; los segundos, realizan un viaje cuyo interés principal es encontrar placer a través de la gastronomía, siendo ésta el recurso primario del destino visitado (Hernández Rojas y Dancausa Millán, 2016).

A partir de estos preceptos, se trata de identificar la existencia de corredores gastronómicos en la provincia de Manabí-Ecuador. Haciendo uso de la bibliografía existente, la realización de una cartografía básica, la cual reúne ciertos criterios comunes, en varios sitios de la zona central de la provincia, se busca caracterizar estos lugares, basados en un concepto de mayor valor agregado, que contribuya al mejoramiento de la calidad del turismo que se realiza actualmente en estos lugares, tomando como atractivo principal a la comida tradi- 
cional de la zona, la cual es una fuente importante de visitas debido a ciertas características como el uso del tradicional del horno de leña y las técnicas de cocción lentas.

\section{Revisión de literatura}

El origen del turismo rural puede situarse en el proceso de concentración urbana. Este es uno de los fenómenos más importantes del siglo xx. La población urbana se ha trasformado en un entorno creado por el hombre y el espacio rural es el entorno natural que ofrece reconexión y armonía convirtiéndose en un refugio de la insatisfacción. En la actualidad, una gran parte de la población urbana se siente atraída por los recursos del medio rural, como el contacto con la naturaleza, el medio ambiente no contaminado, la tranquilidad o el descanso (Zambrana Ríos, 2014). El turismo rural es un sector emergente, que por el lado de demanda turística tiene como objetivo satisfacer las necesidades de los nuevos consumidores turísticos que buscan nuevas emociones (aventuras, lugares históricos, contacto con la naturaleza, etc.) lo que significa cambios en el comportamiento del consumidor (Millán Vásquez de la Torre et al., 2006). Y por el lado de la oferta turística es la fuente de empleo y de recursos económicos de las familias rurales. Al hablar de los ingresos económicos en zonas rurales automáticamente pensamos en que la principal actividad que se desarrolla en ella es la agricultura, sin embargo, en los últimos años, el turismo rural ha ido evolucionando de tal manera que se han generado fuentes de ingresos mediante la utilización de la naturaleza como atractivo para la recepción de visitantes ya sean nacionales o extranjeros. Entre los principales recursos de atracción de las zonas rurales encontramos a la gastronomía como actor primordial del desarrollo.

En el turismo gastronómico, la comida y las especialidades culinarias se han convertido en portadoras de armonía cultural porque se configuran como elementos identificativos de pueblos y regiones (Feo Parrondo, 2005). Defendiendo esta posición, Montoya Sola (2003) asume que se ha recuperado la cocina rural tradicional e incorporado a los atractivos turísticos, enriqueciendo los destinos turísticos del interior y manteniendo la vitalidad del patrimonio cultural. Mediante una dinamización económica el turismo gastronómico emerge en los últimos años, ya que representa una función productora de alimentos la cual necesitará de personal para su funcionamiento ofreciendo nuevas oportunidades en el campo laboral para los habitantes de dicha zona. Del turismo se desprenden un sinnúmero de actividades económicas que son fuentes de ingresos, lo que ha permitido acrecentar las oportunidades de sus habitantes. El turismo gastronómico es un medio para rescatar la comida tradicional debido a que ahora la forma en que los turistas aprecian la comida ha sufrido cambios estructurales dado que buscan un vínculo con sus raíces mediante los sabores y olores del arte culinario. Es así que este tipo de turismo se convierte en una herramienta que ayuda a localizar la comida regional; por lo que, en los últimos años, desde que se ha convertido en un factor clave en el posicionamiento regional de alimentos, se ha vuelto cada vez más importante en el mundo (Vázquez de la Torre Millán y Agudo Gutiérrez, 2010).

Existe una conexión transcendental que relaciona al turismo, la agricultura y la gastronomía; en ese sentido aparecen las rutas gastronómicas y alimentarias, las mismas que son rutas turísticas basadas en la comida que pueda ofrecer determinada zona geográfica. En torno a estos alimentos se construyen productos culturales y de entretenimiento, lo que permite a los turistas explorar la cadena de valor alimentaria desde la producción primaria de los materiales a utilizar para determinado platillo hasta el resultado final; este proceso de elaboración tiene su propia estructura organizativa y cumple con los debidos estándares de calidad (Barrera y Bringas, 2008). Estas rutas están conformadas por productores que reciben a los turistas y les brindan servicios de alimentación en sus locales comerciales; la principal característica de este servicio ofertado es que cada producto turístico es elaborado con los principales bienes agrícolas locales y, por ende, son considerados platos tradicionales agroindustriales (Schlüter \& Thiel Ellul, 2008). La organización de estas rutas va definida en torno a un producto clave y en otros casos alrededor de un grupo de productos que caracteriza la ruta y le otorga identidad cultural y regional, fuente causal de la diferenciación con otras zonas receptoras de turismo.

Barrera (2006) también menciona que las rutas gastronómicas suelen estar asociadas, en la mayoría de los casos, a certificados de calidad, itinerario que permite conocer y disfrutar de forma organizada de los productos turísticos, así como degustar delicias regionales consideradas una identidad cultural. Crear estos segmentos que valorizan los productos nacionales y mezclan los conocimientos ancestrales desarrolla un ambiente atrayente que impulsa la visita de turistas, ya sean nacionales o extranjeros, a sitios con predominantes características.

Esta diversidad de recursos naturales y riqueza natural se ve traducida en atrayentes paisajes, la presencia de balnearios y la diversidad de flora y fauna (Hormaza Muñoz y Torres Rodríguez, 2020). Por otra parte, las 
manifestaciones culturales relacionadas a la gastronomía como es el caso de las preparaciones autóctonas con base en las herramientas de uso gastronómico del montubio manabita (horno de leña, ollas de barro, utensilios de mate), las técnicas de cocción ancestrales, forman parte de una actividad tradicional única de los cantones manabitas (Regalado Espinoza, 2019).

Los corredores turísticos buscan la articulación territorial de determinados espacios turísticos para consolidarlos de manera dinámica (López-López \& Sánchez-Crispín, 2002). Este concepto está basado en un modelo teórico derivado de la geografía regional, conocido como turismo reticular, que permite entender la dinámica geográfico-económica de centros turísticos, con base en el análisis de tres aspectos fundamentales: estructura de un núcleo, los canales espaciales de articulación y los flujos resultantes (Hiernaux, 1989). Desde este punto de partida podemos resumir a los corredores turísticos como ejes catalizadores del desarrollo turístico, por su capacidad de integración de diversos núcleos y flujos turísticos, estos pueden basar su desarrollo a través del uso de rutas temáticas, relacionadas con sus características intrínsecas, las mismas que pueden servir como elemento diferenciador de posicionamiento.

Según su función pueden ser corredores turísticos de traslado y de estadía, los primeros están constituidos por la red de carreteras y caminos de un país a través de los cuales se desplazan los flujos turísticos para cumplir sus itinerarios, mientras que los corredores turísticos de estadía desempeñan una función que viene a ser una combinación de un centro con un corredor turístico, es decir, son superficies alargadas, por lo general, paralelas a las costas de mares o ríos (Cárdenas Tabares, 2006).

El vínculo entre las rutas alimentarias, corredores gastronómicos y demás productos relacionados al agro, junto a las indicaciones geográficas no es caprichoso. Vinos y quesos son los alimentos que acumulan más distintivos de calidad referenciados territorialmente y son también ellos los que muestran mayor cantidad de rutas alimentarias desarrolladas. Las rutas alimentarias, tomadas en sentido amplio como el vínculo construido entre el alimento y el turismo, existen en casi todo el mundo aunque no siempre adquieran carácter formal (Barrera y Bringas, 2008). Se presentan experiencias de rutas alimentarias con el formato que adquieren en Europa, USA y en América Latina reconociendo las intersecciones de forma que existen, pero afrontando la necesidad de establecer políticas particulares de acuerdo con los diversos estadios de desarrollo que se presentan, especialmente en el sector agrario. Como, por ejemplo, se enumeran las siguientes:

- Rutas del vino de España

- Rutas del vino de USA

- El caso de Napa Valley

- Ruta del tequila de México

- Ruta de la sal de México

- Caminos del vino de la Argentina

- Ruta de la yerba de Argentina

Con este antecedente se demuestra que la utilización de los productos agrícolas y gastronómicos tradicionales, poseen un valor incalculable para el turismo, cuyo desarrollo depende de la forma en la que se contribuya a potenciar la producción local, esto sumado al empoderamiento del patrimonio agrario, cultural y natural de las comunidades receptoras, pueden transformarse en un atractivo potencial para nuevos flujos de visitantes, pero es necesario una planificación y gestión de recursos de forma intersectorial, para lograr posicionar un concepto diferenciado, sostenible en el tiempo.

De manera concluyente cabe destacar que los corredores turísticos nacen de la vertiente teórica, propuesta por la geografía del turismo, cuya finalidad es analizar desde una perspectiva territorial las actividades turísticas (Gallegos Jiménez, 2008), esto puede representar un punto de referencia para direccionar la investigación desde la academia y facilitar la inversión pública para las diferentes carteras de Estado. Según Calvopiña Andrade et al. (2017) el término de corredor turístico es confundido o tratado como sinónimo de ruta turística. Los corredores turísticos pueden ser tratados como vías de conexión entre zonas o áreas de una misma región turística, clasificados de acuerdo con su función, como corredor turístico de traslado o estancia (Boullón, 2003). En este caso los corredores gastronómicos representan una oportunidad del territorio, mediante el aprovechamiento de los recursos gastronómicos para el desarrollo de la actividad turística y la generación de autoempleo.

Los corredores gastronómicos representan un concepto relativamente nuevo para la literatura especializada del turismo. La investigación pretende describir las características de este tipo de espacios, los mismos pueden ser tomados en cuenta como una zona de interés turístico o, por qué no, un producto turístico con potencial 
para las operadoras turísticas nacionales. Es necesario la intervención de las autoridades locales y provinciales, para potenciar la imagen de estos lugares, ya que es necesario la implementación de señalética, facilidades turísticas y la promoción de los mismos, para así apuntar a mejores segmentos de mercados y mejorar la calidad de vida de las poblaciones locales.

\section{Materiales y métodos}

El presente estudio es de carácter cualitativo, la investigación es de tipo exploratoria a partir del conocimiento del objeto de estudio, que hasta el momento es muy limitado en la provincia. No existen antecedentes metodológicos que orienten a profundidad la investigación de los corredores gastronómicos en el Ecuador. Sin embargo, existen referencias de importancia que promueven la generación de líneas base para su posterior estudio (URBACT, 2020). Para el trabajo de campo se toma como referencia diversos estudios turísticos en zonas rurales de Manabí (Félix Mendoza y Bayas Escudero, 2016; Félix Mendoza y Ganchozo Lucas, 2020; Félix Mendoza et al., 2019; Félix Mendoza, 2020).

La investigación se realizó en cinco cantones de la zona central de Manabí específicamente en comunidades pertenecientes a estos, las cuales son: La Jagua, perteneciente al cantón Rocafuerte; San Andrés, perteneciente al cantón Chone; Platanales, perteneciente al cantón Bolívar; La Estancilla, perteneciente al cantón Tosagua; y, finalmente, El Badén, perteneciente al cantón Santa Ana.

Estos lugares fueron seleccionados con base en las herramientas de recolección utilizadas que son las entrevistas, donde se definen ciertos criterios de selección, mientras que la muestra de establecimientos se determinó a través las fichas de diagnóstico local y estudio de demanda en comunidades (Ricaurte Quijano, 2009), por lo tanto, el trabajo se dividió en dos partes: una ficha de diagnóstico turístico local realizada a los representantes de las comunidades y una entrevista con autoridades locales y provinciales, enfocada en interpretar a través del trabajo de campo los comportamientos de los turistas y hechos generados en los corredores gastronómicos. A continuación, en la Tabla 1se detalla el esquema de las técnicas e instrumentos de investigación.

Tabla 1. Instrumentos de investigación.

Table 1. Research instruments.

\begin{tabular}{lll}
\hline \multicolumn{1}{c}{ Producto } & \multicolumn{1}{c}{ Elemento que valora } & \multicolumn{1}{c}{ Instrumento aplicado } \\
\hline Criterios de selección & $\begin{array}{l}\text { Identificación de cualidades identita- } \\
\text { rias de la zona }\end{array}$ & $\begin{array}{l}\text { Entrevistas aplicadas a expertos en } \\
\text { turismo de los Gobiernos Autónomos } \\
\text { Municipales de los diferentes cantones }\end{array}$ \\
\hline $\begin{array}{l}\text { Inventario e identificación de oferta y y } \\
\text { demanda turística }\end{array}$ & $\begin{array}{l}\text { Identificación de establecimientos } \\
\text { Identificación de la demanda y perfil } \\
\text { del visitante }\end{array}$ & Ficha de diagnóstico turístico \\
\hline
\end{tabular}

De estas herramientas se determinó los criterios de selección o cualidades identitarias de estas zonas para la selección de los corredores, las mismas que se exponen a continuación:

a) Sitios o comunidades que se ubiquen geográficamente en zonas rurales del centro de la provincia de Manabí.

b) Sitios o comunidades que posean algún tipo de atractivo natural capaz de atraer a visitantes nacionales.

c) Sitios o comunidades que conserven una oferta gastronómica tradicional, utilizando el horno de leña y las técnicas ancestrales de la comida manabita.

d) Sitios o comunidades en las que exista variedad de negocios gastronómicos desde varios años en actividad ininterrumpida de servicio.

e) Sitios o comunidades que cuenten con vías de acceso permanente durante todo el año.

Posteriormente a la selección de los diversos lugares que se identificaron como corredores gastronómicos; se dio paso a generar mapas de cada uno de ellos mediante la utilización del software ArcGIS y Google 
Earth. Para obtener las coordenadas exactas de los corredores gastronómicos se realizó un trabajo de campo en el cual se utilizó el GPS (Garmin eTrex 20x) con el cual se recolectaron las ubicaciones respectivas. También se definió ilustrar un radio de 10 kilómetros, debido a que esta se transforma en una distancia referencial entre estos destinos ubicados en zonas rurales y poblados principales o cabeceras cantonales. El trabajo de campo fue desarrollado durante la semana del 01 al 06 de septiembre del 2020.

\section{Resultados}

El turismo rural es una nueva modalidad que está tomando representatividad en la provincia es por ello que esta investigación contempla el estudio de corredores gastronómicos ubicados en áreas rurales en la zona central de Manabí en donde se han identificado comunidades que cumplen con los criterios de selección propuestos en la metodología, correspondiendo a cinco cantones ubicados en la zona central de Manabí (Figura 1, Tabla 2), estos son: Las Jaguas del cantón Rocafuerte; San Andrés del cantón Chone; Platanales del cantón Bolívar; El Badén del cantón Santa Ana; y La Estancilla del cantón Tosagua.

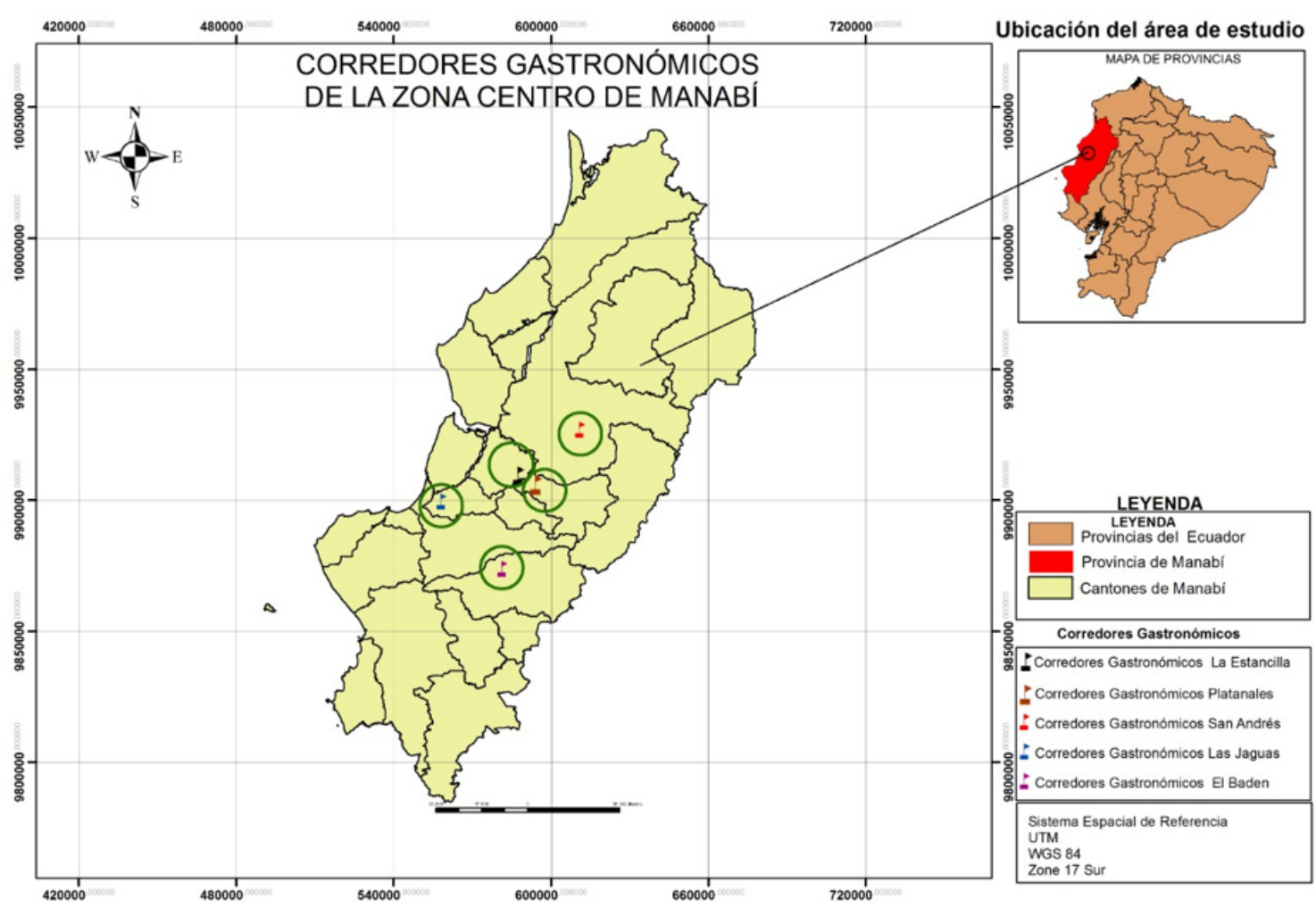

Figura 1. Ubicación geográfica, corredores gastronómicos de la zona central de Manabí.

Figure 1. Geographical location of the food routes in the central area of Manabi.

Tabla 2. Coordenadas de los corredores gastronómicos de la zona centro de Manabí. Table 2. Coordinates of the food routes in the central area of Manabi.

\begin{tabular}{cccc}
\hline Cantón & $\begin{array}{c}\text { Corredor } \\
\text { gastronómico }\end{array}$ & $\begin{array}{c}\text { Coordenadas } \\
\text { Inicio }\end{array}$ & $\begin{array}{c}\text { Coordenadas } \\
\text { Fin }\end{array}$ \\
\hline Bolívar & Platanales & $0593901-9906302$ & $0594805-990615$ \\
Tosagua & La Estancilla & $0586736-9910071$ & $0585401-9911215$ \\
Rocafuerte & Las Jaguas & $0560128-9898232$ & $0556941-9900886$ \\
Santa Ana & El Badén & $0570025-9900886$ & $0579367-9872033$ \\
Chone & San Andrés & $0606053-9926257$ & $0613010-9926959$ \\
\hline
\end{tabular}


De manera general se procede a destacar mediante la Tabla 3 los principales recursos naturales y culturales que se pueden encontrar en estas zonas. Los recursos culturales estarán relacionados a la variedad gastronómica que prevalece en dichos lugares, resaltando algún plato tradicional más trascendente o destacado.

Tabla 3. Atractivos naturales y culturales de los corredores gastronómicos. Table 3. Natural and cultural attractions of the food routes.

\begin{tabular}{|c|c|c|c|c|c|}
\hline & Platanales & La Estancilla & Las Jaguas & El Badén & San Andrés \\
\hline \multirow{2}{*}{$\begin{array}{l}\text { Atractivos } \\
\text { Naturales }\end{array}$} & \multirow{2}{*}{$\begin{array}{l}\text { Río } \\
\text { Balnearios }\end{array}$} & Río & Río & Río & \multirow{2}{*}{$\begin{array}{l}\text { Río } \\
\text { Balnearios } \\
\text { Cascadas }\end{array}$} \\
\hline & & Balnearios & Balnearios & Balnearios & \\
\hline $\begin{array}{l}\text { Producto } \\
\text { emblemático }\end{array}$ & $\begin{array}{l}\text { Platos } \\
\text { derivados } \\
\text { de la gallina } \\
\text { (caldos, secos, } \\
\text { entre otros) }\end{array}$ & La tonga & Morcillas & Majado de verde & $\begin{array}{l}\text { Platos derivados } \\
\text { de la gallina } \\
\text { (caldos, secos, } \\
\text { entre otros) }\end{array}$ \\
\hline $\begin{array}{l}\text { Oferta } \\
\text { gastronómica }\end{array}$ & $\begin{array}{l}\text { - } \text { Suero blar } \\
\text { - } \text { Longaniza } \\
\text { - Seco, cald } \\
\text { - } \text { Chame fri } \\
\text { - } \text { Fritada de } \\
\text { - } \text { Tortillas d } \\
\text { - Bolones, t } \\
\text { - Bollos de } \\
\text { - Mariscos }\end{array}$ & $\begin{array}{l}\text { y morcillas } \\
\text { y tonga de gall } \\
\text { o apanado } \\
\text { hancho } \\
\text { maíz, yuca, par } \\
\text { grillos y empana } \\
\text { escado y chancl } \\
\text { hicharrón, apan }\end{array}$ & $\begin{array}{l}\text { riollas } \\
\text { Imidón y torta } \\
\text { e verde } \\
\text { ceviches) }\end{array}$ & hoclo & \\
\hline $\begin{array}{l}\text { Modo de } \\
\text { preparación }\end{array}$ & Horno de leña, & ollas de barro, u & ios de mate. & & \\
\hline
\end{tabular}

\subsection{Corredor gastronómico del cantón Bolívar-Platanales}

El cantón Bolívar cuenta por tres parroquias: Calceta, Membrillo y Quiroga; caracterizadas esencialmente por la ruralidad, pero con ciertos enfoques urbanos en su cabecera cantonal (Secretaría Nacional de Planificación y Desarrollo [SENPLADES], 2012a). En su conjunto, el cantón Bolívar de acuerdo con el Censo Nacional de Población y Vivienda realizado en el año 2010 por el Instituto Nacional de Estadística y Censos [INEC] posee una población total de 40.735 habitantes.

Dentro del patrimonio material e histórico del cantón que es la expresión física de las manifestaciones culturales, con carga histórica y natural del territorio, en Bolívar se tiene como referencia los balnearios de agua dulce, principalmente el balneario Platanales, el cual es visitado principalmente por la variedad gastronómica existente alrededor del lugar. Este balneario es considerado el más importante que posee el cantón y se encuentra situado a $2 \mathrm{~km}$ del centro de la ciudad, su accesibilidad vehicular es posible durante todo el año. En la Tabla 4 y la Figura 2 se resume la información general obtenida con la utilización de las fichas de caracterización de comunidades.

\subsection{Corredor gastronómico del cantón Tosagua-La Estancilla}

Tosagua es uno de los cantones de la provincia de Manabí. Este cantón cuenta con dos parroquias rurales: Bachillero y Ángel Pedro Giler también conocida como La Estancilla y de acuerdo con los datos del Censo INEC 2010, este cantón presenta una población total de 38.341 habitantes en las áreas urbana y rural (SENPLADES, 2012b). A su vez, su cultura territorial se ve caracterizada por los balnearios distribuidos en sus comunidades, especialmente el balneario La Estancilla, a este recurso natural de las playas del río se suman una serie de atractivos 
Tabla 4. Características generales del corredor gastronómico Platanales.

Table 4. General characteristics of Platanales food route.

\begin{tabular}{lll}
\hline $\begin{array}{l}\text { Oferta de } \\
\text { servicios }\end{array}$ & $\begin{array}{l}\text { Alojamiento } \\
\text { Alimentación }\end{array}$ & $\begin{array}{l}1 \text { camping } \\
10 \text { restaurantes }\end{array}$ \\
\hline & Agua & $\begin{array}{l}\text { Red de agua entubada } \\
\text { Energía eléctrica }\end{array}$ \\
Energía & Vía de acceso pavimentada, señalización vial y \\
básicos & Transportica; bus, camioneta, taxis. \\
& Comunicaciones & $\begin{array}{l}\text { Servicio telefónico y cibercafés } \\
\text { Subcentros de salud y consultorios privados. }\end{array}$ \\
& Sanidad & \\
\hline \multirow{2}{*}{ Gobernanza } & Comités de desarrollo, organizaciones religiosas, clubes \\
\hline \multirow{2}{*}{ Actividades } & Turismo, comercio, agricultura \\
\hline \multirow{2}{*}{ Empleo } & Formal: $10 \%$ & \\
\hline Problemas & Informal: $90 \%$ & Consumo de drogas y alcohol en sitios turísticos, deterioro de los recursos \\
\hline
\end{tabular}

de índole natural y otros relacionados con la gastronomía, como son las tongas, platos a base de gallina criolla, longanizas, los asados, empanadas, y un largo etcétera de exquisiteces que se expenden ya sea en las orillas del río o en locales ubicados en la población (Tabla 5, Figura 3).

Tabla 5. Características generales del corredor gastronómico La Estancilla.

Table 5. General characteristics of La Estancilla food route.

\begin{tabular}{lll}
\hline Oferta de servicios & Alojamiento & 1 hostal \\
& Alimentación & 9 restaurantes \\
\hline \multirow{3}{*}{ Servicios básicos } & Agua & Red de agua entubada \\
& Energía & Energía eléctrica \\
& Transporte & $\begin{array}{l}\text { Vía de acceso pavimentada, señalización } \\
\text { vial, bus, camioneta, taxis. }\end{array}$ \\
& Comunicaciones & Servicio telefónico \\
Gobernanza & Sanidad & Subcentros de salud \\
\hline Actividades & Juntas parroquiales, asociaciones \\
\hline \multirow{2}{*}{ Empleo } & Apoyo GAD parroquial, GAD municipal, GAD provincial \\
\hline Problemas & Turismo, comercio, agricultura \\
\hline
\end{tabular}

\subsection{Corredor gastronómico del cantón Rocafuerte-La Jagua}

El 30 de septiembre de 1852 Rocafuerte logró su cantonización, luego de años de ser parroquia del cantón Portoviejo. Se encuentra ubicado en un lugar privilegiado de la provincia, cerca de balnearios que convergen con lugares turísticos. Su territorio se encuentra enmarado por la ruralidad a nivel general (SENPLADES, 2012b). 
En su totalidad, Rocafuerte posee una población de 33.469 habitantes. El concepto de cultura en el modo de vida de un pueblo o comunidad abarca muchas características, las cuales comprenden desde conocimientos, creencias, costumbres hasta la identificación del hombre como miembro de una sociedad.

Cuando se habla de cultura, no solo se hace referencia a la parte poblacional y sus características, sino al patrimonio material o histórico con el que cuenta un cantón, principalmente relacionado con lo autóctono del mismo, en este caso los balnearios de agua dulce (como el balneario ubicado en el sector "La Jagua") a los que acuden gran cantidad de turistas en busca de recreación y descanso.

El ingreso al balneario no tiene precio, la vía que conduce al atractivo se encuentra lastrada y la vía principal está pavimentada, además, se encontrará una señalización, el tiempo de recorrido desde la entrada del sitio al balneario es de 25 minutos caminando y en auto es de 5 minutos, se puede hacer uso de taxi tomándolo en la vía principal, es un lugar propicio para convivir en armonía con la naturaleza, se puede acceder al servicio de alimentación donde se encontrará diferentes platos de la gastronomía típica del sitio, además tiene un puente de uso peatonal. En la Tabla 6 y la Figura 4 se resume la información general obtenida con la utilización de las fichas de caracterización de comunidades.

Tabla 6. Características generales del corredor gastronómico La Jagua Table 6. General characteristics of La Jagua food route

\begin{tabular}{lll}
\hline \multirow{2}{*}{ Oferta de servicios } & Alojamiento & - \\
& Alimentación & 13 restaurantes \\
\hline \multirow{2}{*}{ Servicios básicos } & Agua & Red de agua entubada \\
& Energía & Energía eléctrica \\
& Transporte & Vía de acceso pavimentada, señalización vial, camioneta, taxis. \\
& Comunicaciones & Servicio telefónico \\
& Sanidad & Dispensario público \\
\hline \multirow{2}{*}{ Gobernanza } & Directiva comunitaria, organizaciones religiosas, clubes \\
\hline Actividades & Apoyo GAD municipal, GAD provincial, Academia, MINTUR, ONGs \\
\hline \multirow{2}{*}{ Empleo } & Agricultura, turismo, comercio & \\
& Formal: $10 \%$ & \\
\hline
\end{tabular}

\subsection{Corredor gastronómico del cantón Santa Ana-El Badén}

El cantón Santa Ana está ubicado geográficamente en el centro este de la provincia de Manabí con una superficie de $1.022 \mathrm{~km}^{2}$. Actualmente Santa Ana está dividido en dos parroquias urbanas: Santa Ana de Vuelta Larga y Lodana, sin embargo, esta última bajo el enfoque demográfico no consta con datos, también está conformada con cuatro parroquias rurales: Ayacucho, Honorato Vásquez, La Unión y San Pablo de Pueblo Nuevo (SENPLADES, 2012c). Este cantón posee una población total de 47.385 habitantes en las áreas urbana y rural.Es transcendental la necesidad de conocer las características culturales de cada territorio para promover el desarrollo del mismo, en el caso del cantón Santa Ana, al enfocarse en la identificación que tiene su población, se observa que, a diferencia de otros cantones, posee un porcentaje de población montubia considerable, esto por la alta población rural en su territorio. En cuanto a las expresiones culturales que forman parte de la identidad cultural que poseen los pueblos o territorios, en Santa Ana, los pobladores pueden reconocer una variedad de expresiones representativas entre ellos el patrimonio material como los balnearios alrededor de sectores gastronómicos, como el balneario El Badén, atractivo turístico de este sector.

La ventaja de ese espacio es que es público y los asistentes pueden disfrutar de sus instalaciones sin ningún costo, así mismo posee grandes ventajas, ya que además de impulsar el turismo ayuda a que el agua del río tenga una especie de remanso y sirva para regar las plantaciones cercanas. En la Tabla 7 y la Figura 5 se resume la información general obtenida con la utilización de las fichas de caracterización de comunidades. 
Tabla 7. Características generales del corredor gastronómico El Badén.

Table 7. General characteristics of El Badén food route.

\begin{tabular}{lll}
\hline $\begin{array}{l}\text { Oferta de } \\
\text { servicios }\end{array}$ & Alojamiento & 1 hostería, 1 hostal \\
\hline Servicios & Agua & 16 restaurantes \\
básicos & Energía & Red de agua entubada \\
& Transporte & Energía eléctrica, gasolineras \\
& Comunicaciones & Vía de acceso pavimentada; señalización vial, bus, camioneta, taxis. \\
& Sanidad & Subcentros de salud y dispensarios médicos \\
\hline Gobernanza & Juntas parroquiales, asociaciones \\
& Apoyo GAD parroquial, GAD municipal, GAD provincial \\
\hline Actividades & Agricultura, turismo, comercio \\
\hline Empleo & Formal: $0 \%$ & \\
& Informal: $100 \%$ & \\
\hline Problemas & Falta de capacitación turística, falta de apoyo a los emprendimientos \\
\hline
\end{tabular}

\subsection{Corredor gastronómico del cantón Chone-San Andrés}

El cantón Chone es también conocido como "La ciudad de los naranjos en flor" debido a los grandes sembríos del fruto. El cantón Chone cuenta con 2 parroquias urbanas: Chone y Santa Rita, también tiene 7 parroquias rurales que son Boyacá, Convento, Canuto, Eloy Alfaro, Ricaurte, San Antonio y Chibunga las cuales se caracterizan por ser territorios que encierran lo rural y urbano (SENPLADES, 2013). De acuerdo con los datos del censo realizado por el INEC en el año 2010, el cantón Chone presenta una población total de 126.491 habitantes en las áreas urbana y rural.

Las características culturales de un pueblo surgen por la aportación social del conjunto de actitudes, creencias, expresiones, hábitos con los cuales se sienten identificados. Así también dentro del cantón se dan manifestaciones culturales ligadas a la gastronomía propia del territorio la cual es degustada por visitantes y turistas en los patrimonios materiales que tiene este cantón como lo son los balnearios de agua dulce y las cascadas que atraviesan las zonas rurales. En especial los balnearios La Guabina, Los cantiles del Jobo, Las cascadas del caracol, Café color tierra y El rey, balnearios ubicados a lo largo del río Mosquito en el corredor gastronómico San Andrés. En la Tabla 8 y la Figura 6 se resume la información general obtenida con la utilización de las fichas de caracterización de comunidades.

Tabla 8. Características generales del corredor gastronómico San Andrés.

Table 8. General characteristics of San Andrés food route.

\begin{tabular}{lll}
\hline Oferta de servicios & Alojamiento & 1 hostería \\
& Alimentación & 10 restaurantes \\
\hline Servicios básicos & Agua & Agua de pozo \\
& Energía & Energía eléctrica \\
& Transporte & Vía de acceso pavimentada, señalización vial y \\
& & turística; bus, camioneta, taxis. \\
& Comunicaciones & Cabina de servicio telefónico y cibercafé \\
& Sanidad & Dispensario público \\
\hline Gobernanza & Organizaciones religiosas & \\
& Apoyo de GAD parroquial, GAD municipal, GAD provincial \\
\hline Actividades & Turismo gastronómico, turismo de aventura, agricultura, ganadería \\
Empleo & Formal: 0 \% & \\
\hline Problemas & Informal: $100 \%$ & \\
\hline
\end{tabular}




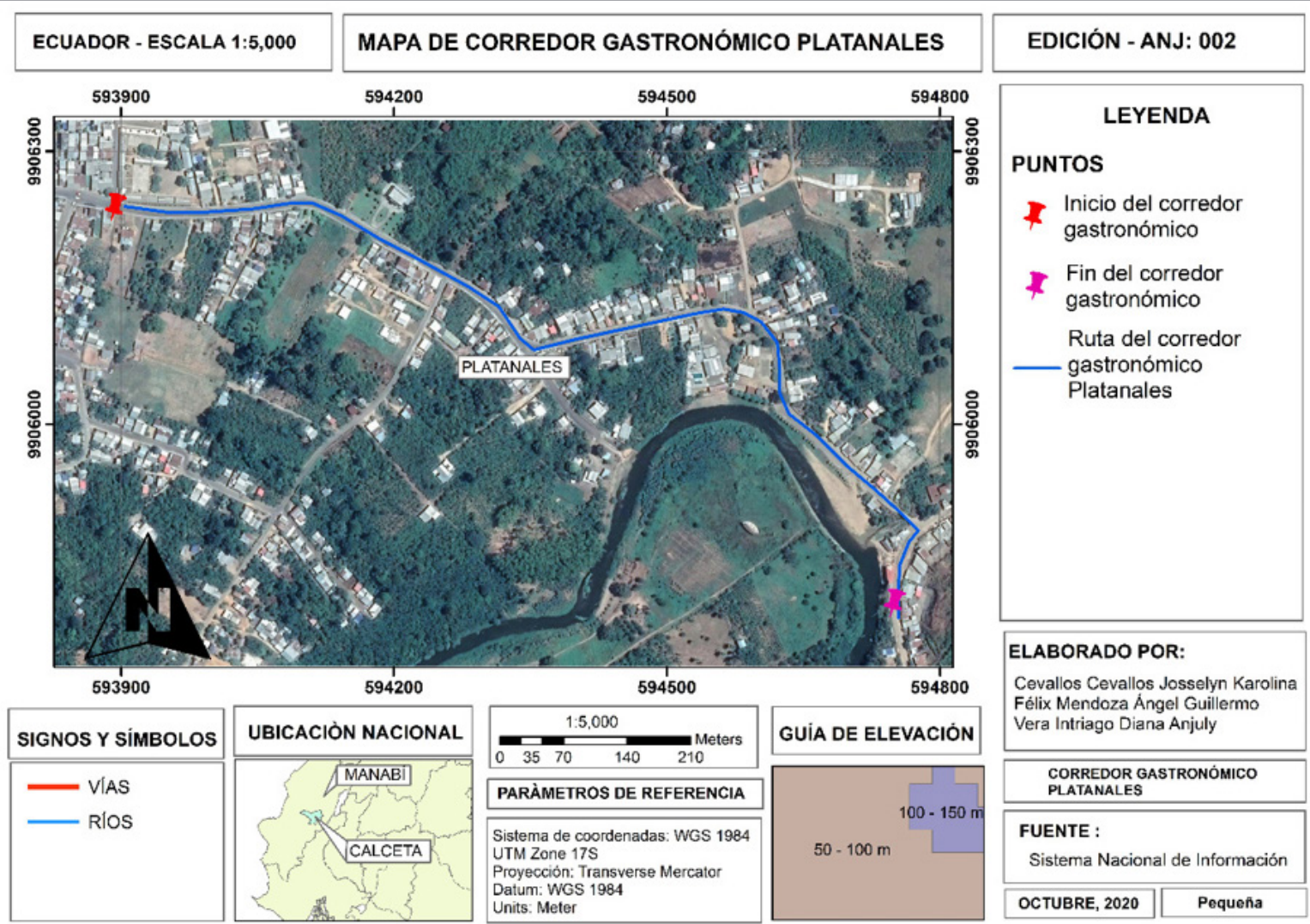

Figura 2. Mapa de caracterización del corredor gastronómico Platanales.

Figure 2. Characterization map of the Platanales food route.

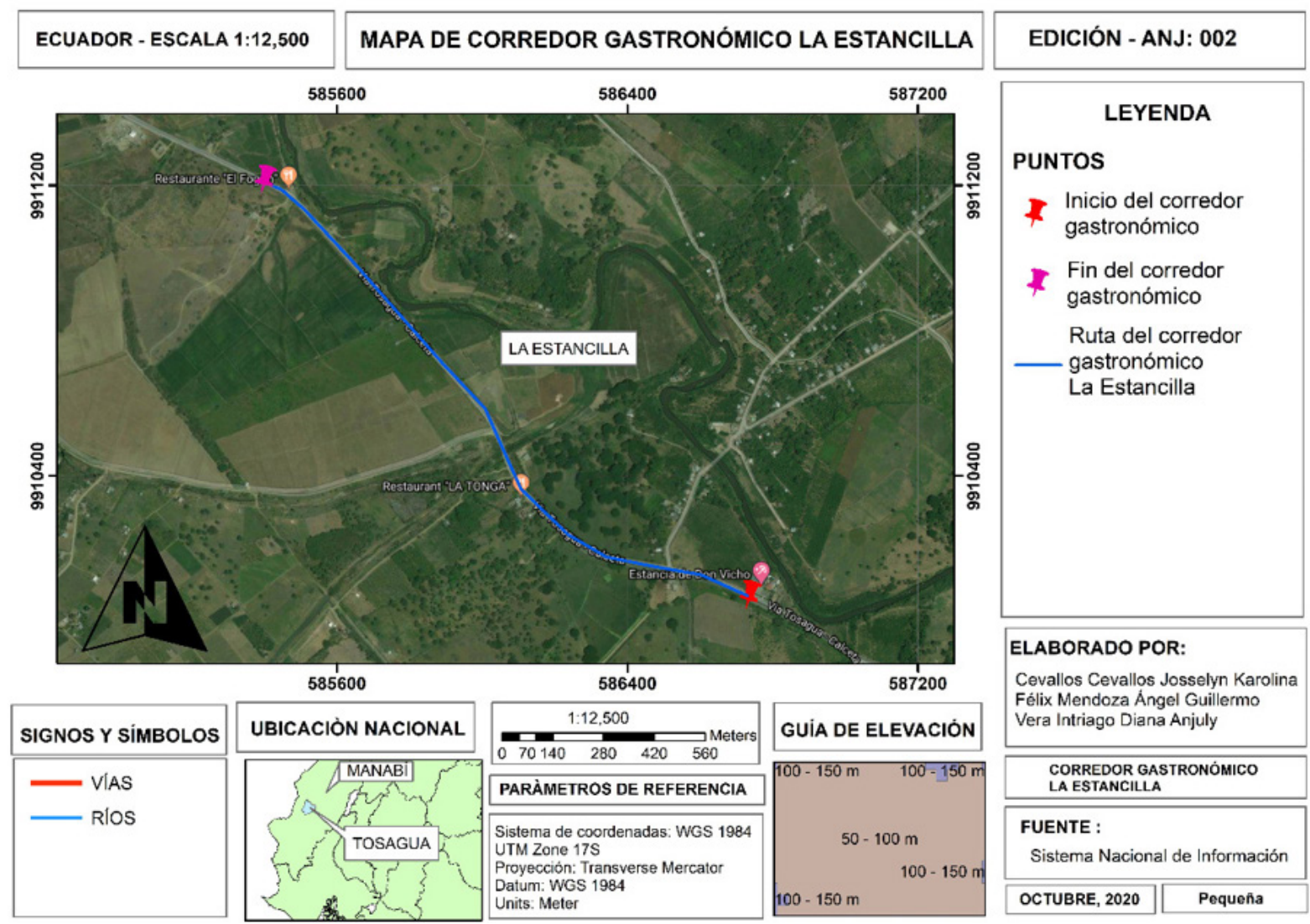

Figura 3. Mapa de caracterización del corredor gastronómico La Estancilla.

Figure 3. Characterization map of La Estancilla food route. 


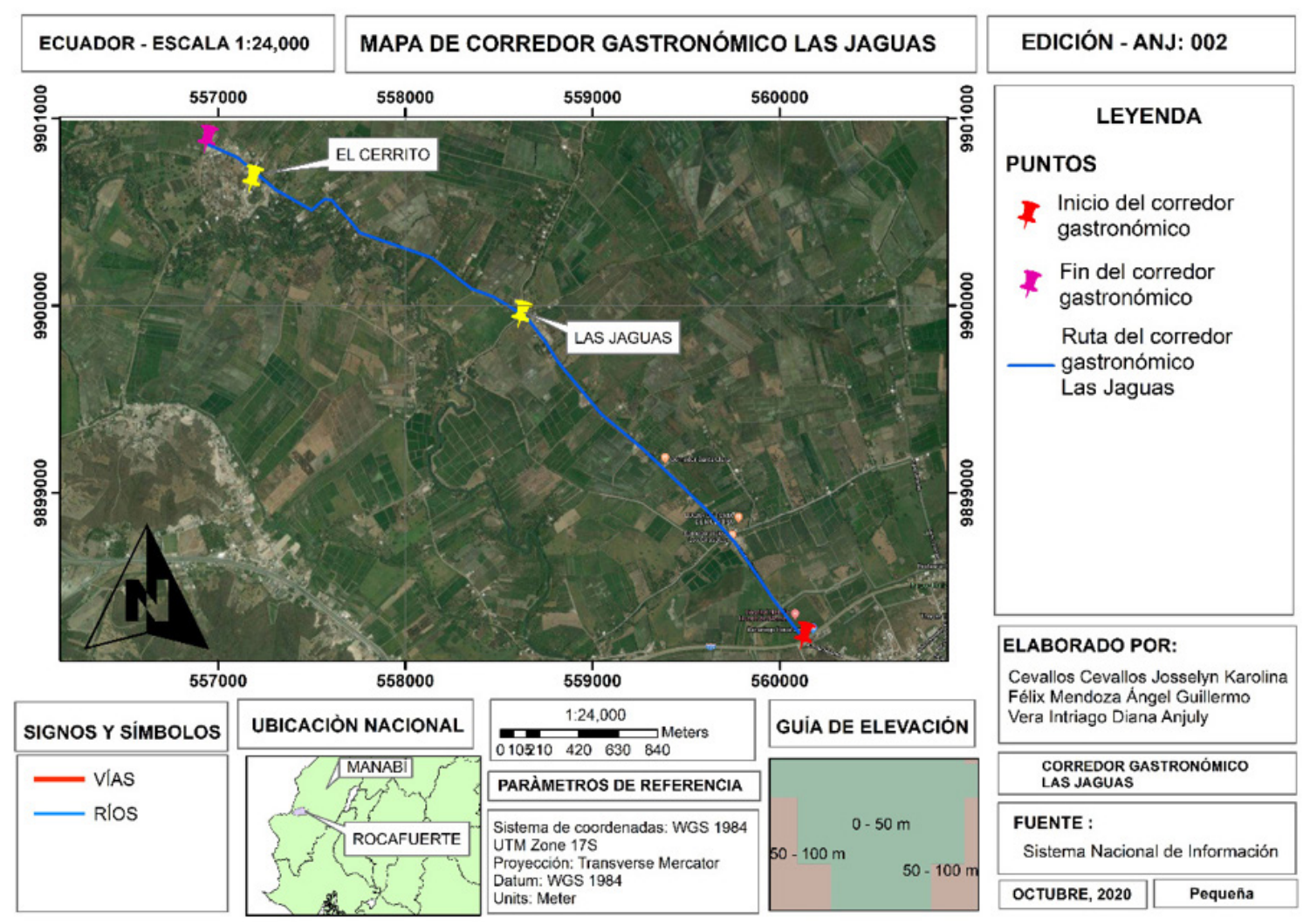

Figura 4. Mapa de caracterización del corredor gastronómico La Jagua. Figure 4. Characterization map of La Jagua food route.

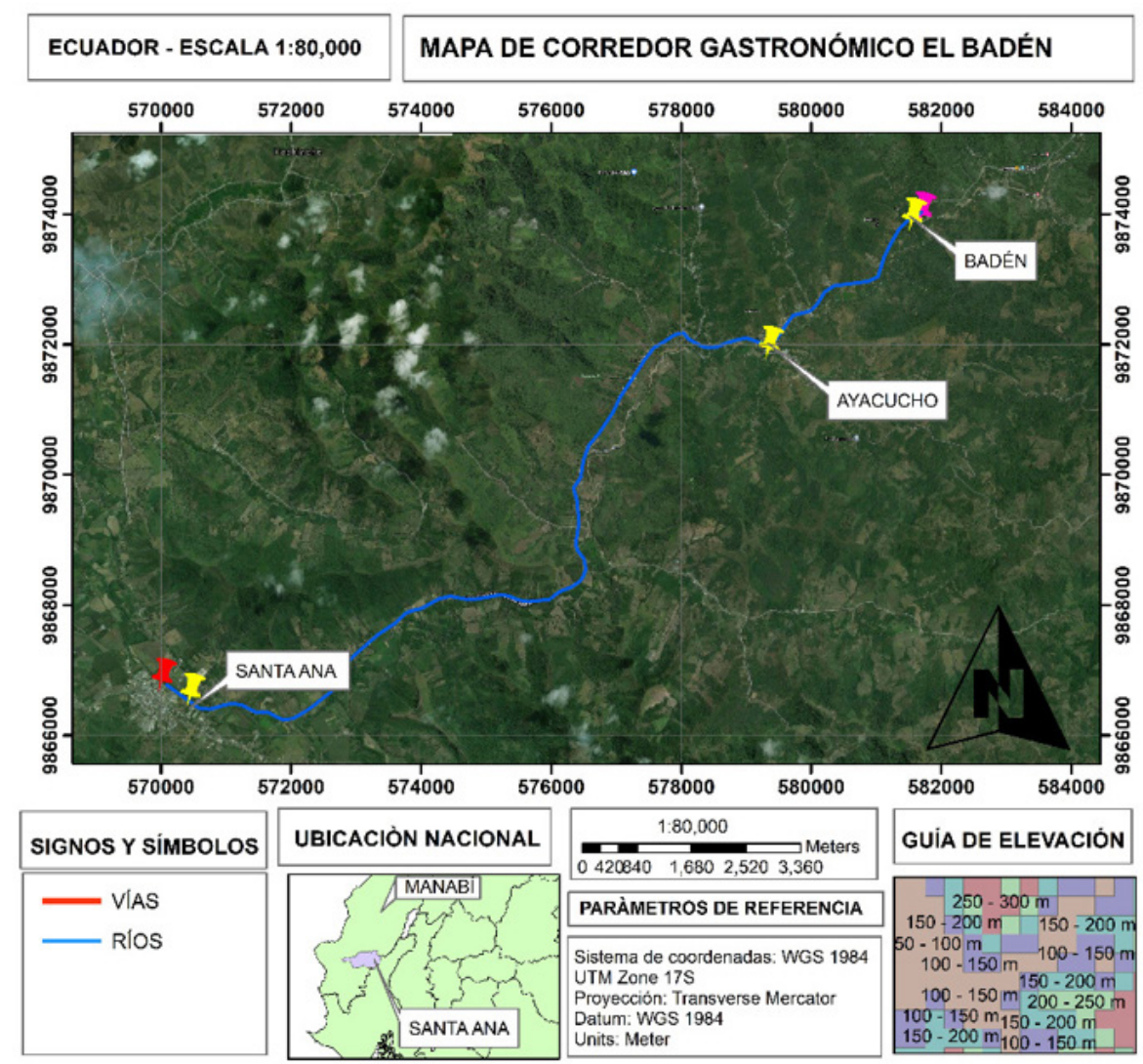

EDICIÓN - ANJ: 002

LEYENDA

\section{PUNTOS}

I Inicio del corredor gastronómico

Fin del corredor gastronómico

Ruta del corredor

- gastronómico El Badén

\section{ELABORADO POR:}

Cevallos Cevallos Josselyn Karolina Félix Mendoza Ángel Guillermo Vera Intriago Diana Anjuly

\begin{tabular}{|c|}
\hline $\begin{array}{l}\text { CORREDOR GASTRONÓMICO } \\
\text { EL BADÉN }\end{array}$ \\
\hline \hline FUENTE : \\
Sistema Nacional de Información \\
\hline OCTUBRE, 2020 \\
\hline
\end{tabular}

Figura 5. Mapa de caracterización del corredor gastronómico El Badén. Figure 5. Characterization map of El Badén food route. 


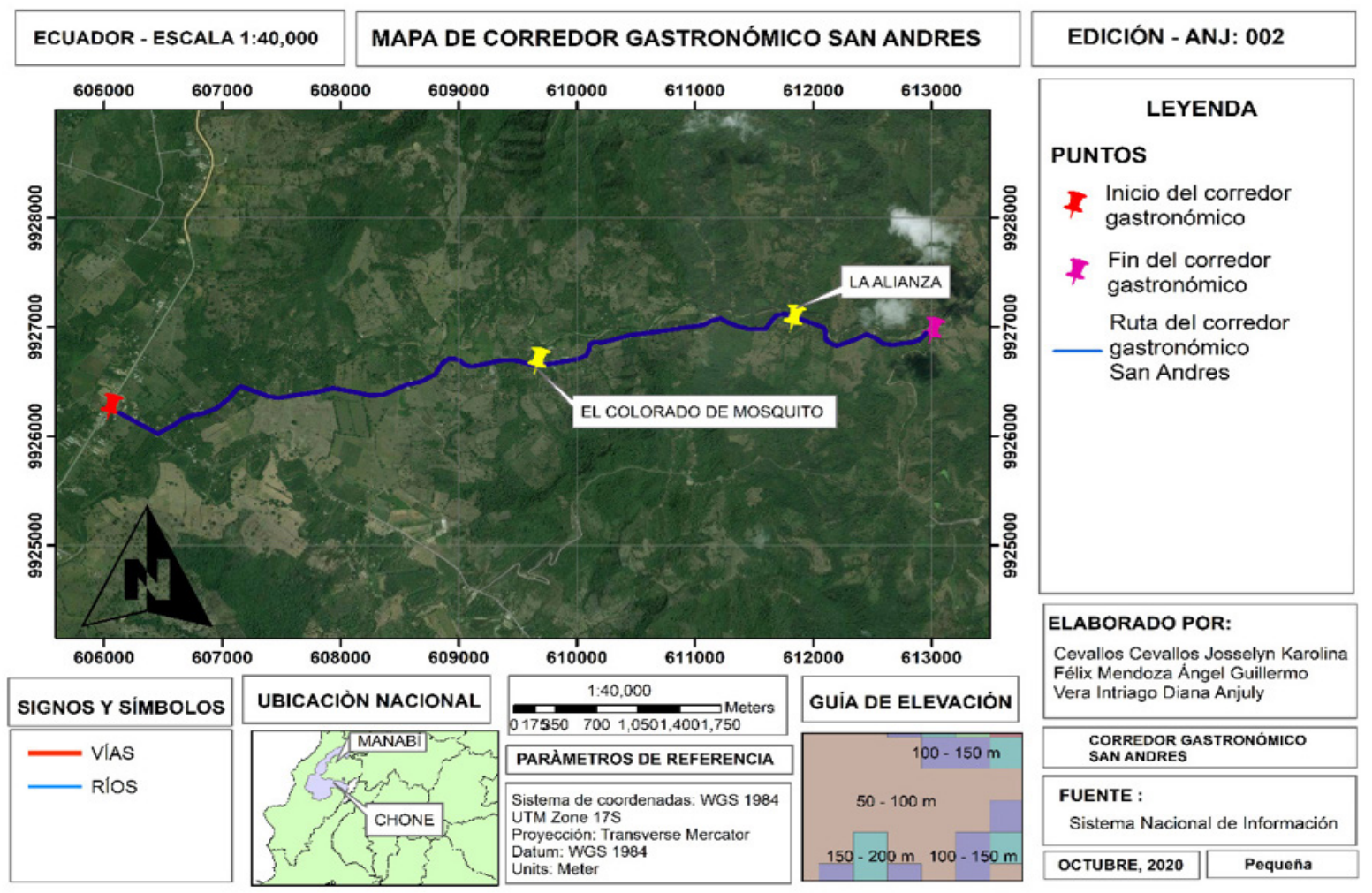

Figura 6. Mapa de caracterización del corredor gastronómico San Andrés. Figure 6. Characterization map of San Andrés food route.

\section{Discusión}

Como bien se identificaba al inicio de la introducción, pese a los problemas de planificación en los territorios, se debe reconocer el aporte del turismo a la revitalización económica del mismo (Brida et al., 2017). Esto no es discutible cuando encontramos comunidades como los corredores gastronómicos de la zona central de Manabí que, a pesar de estar desatendidas por las autoridades locales, muestran su mejor esfuerzo a través de la puesta en valor de la gastronomía, logrando una inyección económica importante en territorios históricamente deprimidos.

Se logra identificar esa conexión importante la cual relaciona al turismo, la agricultura y la gastronomía (Barrera \& Bringas, 2008), debido a que la ubicación geográfica de los corredores gastronómicos se la determina en zonas netamente rurales, lugares especializados en la agricultura y ganadería, donde existen recursos naturales diversos, pero a su vez se incorpora un elemento más como las tradiciones culturales (Tabla 9). Manabí ha sido considerada por muchos años una de las provincias del Ecuador con la mayor riqueza gastronómica ancestral.

Tabla 9. Principales factores internos de los corredores gastronómicos.

Table 9. Main internal factors of food route.

\begin{tabular}{|c|c|}
\hline Potencialidades & Limitaciones \\
\hline - Extensivo emporio de riqueza cultural. & $\begin{array}{l}\text { - Falta de señalética turística que guíe al visitante a los recursos } \\
\text { naturales. }\end{array}$ \\
\hline $\begin{array}{l}\text { - Mantenimiento de expresiones de la cultura popular manabita, entre lo } \\
\text { autóctono, la mezcla y combinación de raíces ancestrales. }\end{array}$ & $\begin{array}{l}\text { - Éxodo rural de los habitantes de las zonas más pobres, que } \\
\text { generalmente se encuentran en comunidades pequeñas. }\end{array}$ \\
\hline $\begin{array}{l}\text { - Expresión cultural de su gastronomía, representadas en platos típicos } \\
\text { como la tonga, caldo y seco de gallina criolla, la cuajada, entre otras. }\end{array}$ & $\begin{array}{l}\text { - La aculturación, es decir, la pérdida de identidad cultural y sentido de } \\
\text { propiedad del lugar, sobre todo en los jóvenes. }\end{array}$ \\
\hline $\begin{array}{l}\text { - Numerosos recursos naturales como cascadas en la zona alta, los ríos, } \\
\text { belleza paisajística y sus balnearios. }\end{array}$ & - Poca experiencia en ciertos sectores respecto a la rama turística. \\
\hline \multirow{4}{*}{$\begin{array}{l}\text { - Abundante producción agrícola y ganadera, articuladores de la } \\
\text { economía del agro circulante y caracterizado por una gran capacidad } \\
\text { productiva. }\end{array}$} & - Personal enfocado solo en la atención, no en el ambiente de atención. \\
\hline & - Falta de políticas para el desarrollo del turismo en las zonas rurales. \\
\hline & - Pérdida paulatina de los recursos naturales. \\
\hline & - Desempleo \\
\hline
\end{tabular}


La generación de la línea base para el estudio de estos corredores gastronómicos (URBACT, 2020), ha tenido que ser adaptada a las necesidades locales; debido a la falta de datos oficiales y a la poca formalidad del sector turístico en zonas rurales, se ha tenido que improvisar herramientas y técnicas que faciliten una caracterización más sencilla del objeto de estudio, sin que se pierda la representatividad (Ricaurte Quijano, 2009). Las metodologías de estudios en zonas rurales (Félix Mendoza y Bayas Escudero, 2016; Félix Mendoza y Ganchozo Lucas, 2020; Félix Mendoza et al., 2019; Félix Mendoza, 2020) han sido de mucha utilidad, pero aun así existen muchos vacíos por llenar en futuros estudio. Se plantea como una prioridad la generación de observatorios de turismo rural o de interior en el Ecuador, para que se facilite la utilización de datos, trabajo que podría integrarse con el Ministerio de Turismo del Ecuador [MINTUR].

Documentos oficiales como los Planes de Desarrollo y Ordenamiento Territorial [PDOT], INEC e informes de la SENPLADES, han sido de gran ayuda para la caracterización general de estos destinos, aunque para la actualidad los últimos datos oficiales quedan un poco alejados de la realidad, ya que por ejemplo los reportes oficiales del censo datan del 2010; han pasado más de 10 años, pero aún siguen siendo oficiales y son los más recientes. Lo mismo con ciertos PDOT y otros documentos oficiales; por lo que se hace necesario seguir haciendo amplios levantamientos de información, especialmente en territorios rurales.

La funcionalidad de los corredores turísticos es la de articular determinados espacios turísticos para consolidarlos de manera dinámica (López-López \& Sánchez-Crispín, 2002). Esto podría dar espacio para próximas investigaciones que vayan encaminadas a la integración de estos corredores gastronómicos en la zona centro de Manabí, creando un clúster importante relacionado a las tradiciones culturales, llevadas de la mano de la gastronomía, lo que podría generar líneas de investigación interesantes para la academia y los organismos de gestión y promoción.

Estos corredores gastronómicos identificados (Platanales, La Estancilla, La Jagua, El Badén y San Andrés), no son los únicos de la zona centro de la provincia, pero sí son los más importantes y cumplen con los criterios construidos en conjunto entre los investigadores y las autoridades locales. Queda la puerta abierta para un gran estudio que englobe los corredores gastronómicos de toda la provincia, incluyendo las zonas costeras, que no fueron tomadas en cuenta en este estudio. Para la eficiencia de la adopción de esta terminología se deben generar acercamientos con los representantes de las entidades públicas provinciales, para que se contemplen estas zonas como destinos turísticos con potencial, y sean objeto de inversiones públicas para mejorar sus operaciones.

\section{Conclusiones}

Los corredores gastronómicos representan un concepto nuevo para el estudio del turismo en la provincia de Manabí; y relativamente nuevo a nivel nacional. Se encuentran estudios importantes que vinculan al turismo y la gastronomía en países como México y España. Pero las bases de esta relación va mucho más allá, en la literatura latinoamericana se encuentra un antecedente importante con las rutas agroalimentarias, concepto que generó mucha investigación relacionada a la creación de valor de ciertos productos agrícolas como el vino, el café, el tequila, el chocolate, los mismos que son capaces de generar el interés de flujos de visitantes por conocer las condiciones de vida de los productores, desde las técnicas de cultivo y toda la cadena de valor que se desenvuelve en sus territorios. Esto también da origen a las denominaciones de origen y patentes en territorio. La gastronomía tradicional alrededor del mundo tiene características que la hacen única a sus territorios, por lo que esa singularidad hace posible que en pequeñas distancias de viajes se encuentre grandes diferencias en la preparación y formas de cocción de los alimentos. En el caso de Manabí encontramos la presencia de los balnearios turísticos, alrededor de ellos se han dado las condiciones adecuadas para la creación de corredores gastronómicos, debido a la variedad de platos típicos que se ofertan, esto es visto por los pobladores como una oportunidad para la generación de ingresos económicos para las familias que viven en estos lugares. Lo cual debe ser fortalecido por las autoridades locales y provinciales.

Mediante visitas de campo, fichas de observación y entrevistas con autoridades locales de los cantones de la zona centro de Manabí, se lograron validar ciertos criterios que ayudaron a identificar zonas geográficas que son capaces de atraer visitantes locales y nacionales, estas han sido denominadas corredores gastronómicos, debido a que la gastronomía se ha transformado en su principal atractivo, el mismo que se ve complementado por otros recursos y servicios. Estos corredores gastronómicos fueron georreferenciados y graficados, utilizando imágenes satelitales para graficar mapas que ilustran su recorrido. Se encontró una muestra representativa de establecimientos de alimentación (58 restaurantes), acompañada de 5 establecimientos de hospedaje de 
diversos tipos (camping, hostal y hostería). Los mismos que poseen un acceso adecuado durante todo el año, junto a servicios básicos como energía eléctrica, agua potable y cobertura telefónica móvil. Características que hacen de estas zonas potenciales atractivos turísticos, que necesitan del soporte de las autoridades para su adecuada promoción, formación y equipamiento, para que puedan ser transformados de destinos de visitas cortas a destinos de pernoctación, y de esta manera ampliar la cadena de valor turística alrededor de estos.

A pesar de todas las características importantes identificadas en estos lugares, también existen serias limitaciones que no permiten el desarrollo socio económico de estos corredores gastronómicos. El éxodo rural provocado por las pocas oportunidades laborales es uno de los más preocupantes problemas en estas zonas, debido a que la mayoría de los recursos que encontramos en las zonas rurales dependen de la existencia de comunidades que continúen con los procesos económicos y culturales en los territorios. La delincuencia y consumo de sustancias ilegales representa otra debilidad que limita el desarrollo de actividades productivas como el turismo. Por último la falta de implementación de facilidades turísticas provoca que no existan más actividades vivenciales que promuevan el interés de los visitantes por alargar su estancia, esto unido a la poca promoción y falta de apoyo de las autoridades locales y provinciales, no han permitido que estos destinos diversifiquen su cartera de clientes, que pese a todas estas limitaciones mantienen un flujo sumamente interesante de visitantes que dinamizan la economía local y cuyo estudio a profundidad ha sido estudiado pero está reservado para una próxima difusión de resultados.

\section{Contribuciones de los autores}

- Ángel Guillermo Félix Mendoza: conceptualización, investigación, metodología, supervisión, redacción - borrador, redacción - revisión y edición.

- Diana Anjuly Vera Intriago: administración del proyecto, recursos, análisis formal, curación de datos, validación, visualización.

- Josselyn Karolina Cevallos Cevallos: recursos, análisis formal, curación de datos, validación, visualización.

\section{Referencias}

Aguirregoitia Martínez, A., \& Fernández-Poyatos, M. D. (2017). La gastronomía como recurso turístico en la provincia de Alicante. International Journal of Scientific Management and Tourism, 3(3), 25-48. http:// www.ijosmt.com/index.php/ijosmt/article/view/246

Barrera, E. (2006). Rutas alimentarias. Una estrategia cultural para el desarrollo rural mexicano. Patrimonio Cultural y Turismo. Cuadernos 15. Itinerarios culturales y rutas del patrimonio, 15, 67-86. https://www. cultura.gob.mx/turismocultural/cuadernos/cuaderno15_1.php

Barrera, E., \& Bringas, O. (2008). Las rutas alimentarias: Una arquitectura turística basada en la identidad de los alimentos. Gastronomic Sciences, 3(706), 1-11.

Boullón, R. (2003). Ecoturismo: sistemas naturales y urbanos. Ediciones Turísticas de Mario Banchik.

Boullón, R. (2006). Planificación del espacio turístico. Editorial Trillas.

Brida, J. G., Rodríguez-Brindis, M. A., Mejía-Alzate, M. L., \& Zapata-Aguirre, S. (2017). La contribución directa del turismo al crecimiento económico de Colombia: análisis por ramas características del sector utilizando la Cuenta Satélite de Turismo-CST. Revista de Estudios Regionales, 109, 121-138. http:// www.revistaestudiosregionales.com/documentos/articulos/pdf-articulo-2522.pdf

Calvopiña Andrade, D. M., Velasco Samaniego, V. M., Cali Pereira, M. I., \& Sampedro Arrieta, M. (2017). Estudio de la incidencia en el desarrollo local de corredores turísticos. Caso de estudio cantón Pallatanga, provincia Chimborazo, Ecuador. TURYDES: Revista sobre Turismo y Desarrollo local sostenible, 10(22). https://www.eumed.net/rev/turydes/22/turismo-canton-pallatanga.html

Cárdenas Tabares, F. (2006). Proyectos turísticos. Localización e inversión. Editorial Trillas.

Félix Mendoza, Á. G. (2020). La comodificación del patrimonio agrario desde la academia. Caso de estudio: "fincas agroturísticas". En Turismo y desarrollo rural. Realidades diversas y propuestas sostenibles desde América Latina (pp. 59-89). Ediciones Uleam.

Félix Mendoza, A. G., \& Bayas Escudero, J. P. (2016). El agroturismo como dinamizador de destinos turísticos en el centro de Manabí. En A. E. Mendoza Tarabó (Coord.), Investigaciones turísticas del Ecuador: 
Fortaleciendo la innovación en los destinos turísticos (pp. 105-117). Universidad Península de Santa Elena, Cecatere.

Félix Mendoza, Á. G., \& Ganchozo Lucas, M. P. (2020). Herramientas de planificación participativas para el desarrollo turístico comunitario: Caso de estudio. Siembra, 7(2), 032-046. https://doi.org/10.29166/siembra.v7i2.2189

Félix Mendoza, Á. G., Zambrano Laaz, M. Y., \& Vera Mejía, T. R. (2019). Visitas a Represas: Percepción y necesidades para el turismo. Turismo, Desarrollo y Buen Vivir. Revista de Investigación de la Ciencia Turística - RICIT, 13, 42-61. https://revistas.udetonline.com/index.php/ricit/article/view/61

Félix, A., García Reinoso, N., \& Vera, R. (2020). Participatory diagnosis of the tourism sector in managing the crisis caused by the pandemic ( COVID-19). Revista interamericana de ambiente y turismo, 16(1), 66-78. https://dx.doi.org/10.4067/s0718-235x2020000100066

Feo Parrondo, F. (2005). Turismo gastronómico en Asturias. Cuadernos de Turismo, 15, 77-96. https://revistas.um.es/turismo/article/view/18501

Gallegos Jiménez, O. (2008). Organización espacial del corredor turístico Veracruz-Boca del Río. Teoría y Praxis, 4(5), 171-186. https://doi.org/10.22403/uqroomx/typ05/13

Hernández Rojas, R. D., \& Dancausa Millán, M. G. (2016). Tourism Observatory: a need for management and gastronomy of Cordoba province. International Journal of Scientific Management and Tourism, 2(4), 6979. http://www.ijosmt.com/index.php/ijosmt/article/view/159

Hiernaux, N. D. (1989). El espacio reticular del turismo en México. Geografía y desarrollo, 2(3), 31-39.

Hormaza Muñoz, D. G., \& Torres Rodríguez, R. M. (2020). El patrimonio cultural en los servicios turísticos en la provincia de Manabí, Ecuador. PASOS Revista de Turismo y Patrimonio Cultural, 18(3), 385-400. https://doi.org/10.25145/j.pasos.2020.18.027

López-López, Á., \& Sánchez-Crispín, Á. (2002). Canales espaciales de articulación en el corredor turístico Los Cabos, Baja California Sur, México. Cuadernos de Turismo, 9, 53-66. https://revistas.um.es/turismo/article/view/21961

Millán Vásquez de la Torre, G., Morales Fernández, E., \& Pérez Naranjo, L. (2014). Turismo gastronómico, Denominaciones de Origen y desarrollo rural en Andalucía: situación actual. Boletín de la Asociación de Geógrafos Españoles, 65, 113-137. https://doi.org/10.21138/bage.1746

Montoya Sola, T. (2003). La gastronomía tradicional en el turismo rural. En J. M. Martínez López (Coords.) Historia de la alimentación rural y tradicional: recetario de Almería (pp. 159-161). Instituto de Estudios Almerienses.

Organización Mundial del Turismo [OMT]. (2020). Barómetro OMT del Turismo Mundial y anexo estadístico, Enero 2020. UNWTO World Tourism Barometer - Barómetro OMT del Turismo Mundial (Versión española), 18(1), 1-48. https://doi.org/10.18111/wtobarometeresp.2020.18.1.1

Regalado Espinoza, L. (2019). Manabi y su comida milenaria (2a ed.). Ediciones Uleam.

Ricaurte Quijano, C. (2009). Manual para el diagnóstico turístico local. Guía para planificadores. Escuela Superior Politécnica del Litoral.

Schlüter, R. G., \& Thiel Ellul, D. (2008). Gastronomía y turismo en Argentina. Polo gastronómico Tomás Jofré. PASOS Revista de Turismo y Patrimonio Cultural, 6(2), 249-268. https://doi.org/10.25145/j.pasos.2008.06.019

Secretaría Nacional de Planificación y Desarrollo [SENPLADES]. (2012a). Memoria técnica cantón Bolivar. Ptoyecto: "Generación de geoinformación para la gestión del territorio a nivel nacional". SENPLADES.

Secretaría Nacional de Planificación y Desarrollo [SENPLADES]. (2012b). Memoria técnica cantón Rocafuerte. Proyecto: "Generación de geoinformación para la gestión del territorio a nivel nacional". SENPLADES.

Secretaría Nacional de Planificación y Desarrollo [SENPLADES]. (2012c). Memoria técnica cantón Santa Ana. Proyecto: "Generación de geoinformación para la gestión del territorio a nivel nacional". SENPLADES

Secretaría Nacional de Planificación y Desarrollo [SENPLADES]. (2013). Memoria técnica cantón Chone. Proyecto: "Generación de geoinformación para la gestión del territorio a nivel nacional". SENPLADES

URBACT. (2020). Food Corridors: Baseline Study. European Union. https://urbact.eu/sites/default/files/media/food_corridors_baseline_study_high_quality.pdf

Vázquez de la Torre Millán, M. G., \& Agudo Gutiérrez, E. M. (2010). El turismo gastronómico y las denominaciones de origen en el sur de España: oleoturismo. Un estudio de caso. PASOS Revista de Turismo y Patrimonio Cultural, 8(1), 91-112. https://doi.org/10.25145/j.pasos.2010.08.008

Zambrana Ríos, V. (2014). El turismo rural una modalidad creciente de turismo. Saberes bolivianos. http:// saberesbolivianos.com/investigadores/vzambrana/E1\%20turismo\%20rural\%20una\%20modalidad\%20 creciente $\% 20 \mathrm{de} \% 20$ turismo.pdf 